\title{
$A B C C$ transporters mediate insect resistance to multiple Bt toxins revealed by bulk segregant analysis
}

Youngjin Park ${ }^{1 \dagger}$, Rosa M González-Martínez ${ }^{2 \dagger}$, Gloria Navarro-Cerrillo², Maissa Chakroun ${ }^{2}$, Yonggyun Kim , Pello Ziarsolo ${ }^{3}$, Jose Blanca ${ }^{3}$, Joaquin Cañizares ${ }^{3}$, Juan Ferré ${ }^{2}$ and Salvador Herrero ${ }^{2^{*}}$

\begin{abstract}
Background: Relatively recent evidence indicates that $A B C C 2$ transporters play a main role in the mode of action of Bacillus thuringiensis (Bt) Cry1A-type proteins. Mapping of major Cry1A resistance genes has linked resistance to the ABCC2 locus in Heliothis virescens, Plutella xylostella, Trichoplusia ni and Bombyx mori, and mutations in this gene have been found in three of these Bt-resistant strains.

Results: We have used a colony of Spodoptera exigua (Xen-R) highly resistant to a Bt commercial bioinsecticide to identify regions in the $S$. exigua genome containing loci for major resistance genes by using bulk segregant analysis (BSA). Results reveal a region containing three genes from the $A B C C$ family ( $A B B C 1, A B B C 2$ and $A B B C 3$ ) and a mutation in one of them (ABBC2) as responsible for the resistance of $S$. exigua to the $B t$ commercial product and to its key Spodoptera-active ingredients, Cry 1 Ca. In contrast to all previously described mutations in ABCC2 genes that directly or indirectly affect the extracellular domains of the membrane protein, the ABCC2 mutation found in S. exigua affects an intracellular domain involved in ATP binding. Functional analyses of $A B B C 2$ and $A B B C 3$ support the role of both proteins in the mode of action of $B t$ toxins in S. exigua. Partial silencing of these genes with dsRNA decreased the susceptibility of wild type larvae to both Cry 1 Ac and Cry $1 \mathrm{Ca}$. In addition, reduction of $A B B C 2$ and $A B B C 3$ expression negatively affected some fitness components and induced up-regulation of ary/phorin and repat5, genes that respond to $B t$ intoxication and that are found constitutively up-regulated in the Xen- $R$ strain.

Conclusions: The current results show the involvement of different members of the $A B C C$ family in the mode of action of $B$. thuringiensis proteins and expand the role of the $A B C C 2$ transporter in $B$. thuringiensis resistance beyond the Cry1A family of proteins to include Cry1Ca.
\end{abstract}

Keywords: Bt resistance, ABCC2 transporter, Cry toxins

\section{Background}

Genes coding for insecticidal proteins from the bacterium Bacillus thuringiensis (Bt) have been transferred to plants to protect them from the attack of insect pests $[1,2]$ and the global impact of this strategy has been unprecedented in plant biotechnology. Unfortunately, and similarly with the history of chemical insecticides, insects have developed resistance to $B$. thuringiensis crystal proteins (Cry proteins) when exposed to either foliar $B$.

\footnotetext{
*Correspondence: sherrero@uv.es

${ }^{\dagger}$ Equal contributors

2Department of Genetics, Universitat de València, Dr Moliner 50, 46100

Burjassot, Spain

Full list of author information is available at the end of the article
}

thuringiensis sprays or transgenic crops (Bt-crops) [3-5]. The long lasting benefits of $B$. thuringiensis insecticides and Bt-crops will mostly depend on the understanding of the mode of action of Cry proteins and of the biochemical and genetic bases of insect resistance.

All B. thuringiensis crystal proteins (Cry proteins) which are toxic to target insects share general traits in their mode of action: solubilization in the midgut, activation by gut proteases, binding to membrane surface proteins (generally referred to as 'receptors') [6,7]. Susceptible insects have epitopes in their membrane receptors that are recognized by sequences of the Cry proteins. This is probably the main reason why Cry proteins are not harmful to non-target 
insects [8]. The key role of membrane receptors has also become evident when studying the biochemical basis of insect resistance to Cry toxins. Most cases of high level resistance to Cry1A proteins have been shown to be due to a decrease of toxin binding to midgut receptors [9].

Two approaches have been undertaken to characterize membrane proteins involved in the toxicity of Cry proteins. Formerly, the approach was biochemical, and it allowed for the characterization of receptors such as cadherin, aminopeptidase N (APN), and alkaline phosphatase (ALP) [10], among others. The occurrence of such a variety of receptors has been explained by integrating them in a 'toxicity pathway' that implies their participation in a sequential way [7]. In the most accepted model, binding to cadherin is required for the Cry proteins to oligomerize and then bind to other receptors, such as APN and ALP, which favor toxin insertion into the membrane. There is evidence supporting the participation of cadherin and APN in the toxicity of Cry proteins $[11,12]$. Furthermore, mutations conferring resistance to proteins from the Cry1A family have been found in the cadherin gene from Heliothis virescens [13], Helicoverpa armigera [14,15] and in Pectinophora gossypiella [16]. Similarly, mutations or reduced expression of apn genes have been found in resistant insects from Spodoptera exigua [17], Diatraea saccharallis [18] and Trichoplusia ni [19].

Another membrane protein, identified as an $\mathrm{ABCC} 2$ transporter, was found related to the mode of action of CrylA-type proteins using a genetic approach to identify major genes involved in resistance in $H$. virescens [20]. Later on, mutations in the $A B C C 2$ gene were found in Cry1A resistant colonies from three other insect species: Plutella xylostella [21], T. ni [21], and Bombyx mori [22]. Further evidence for the involvement of the $\mathrm{ABCC} 2$ transporter in Cry1A toxicity came from functional studies with transfected cultured cells [23]. Although mutations in either the cadherin or in the $A B C C 2$ gene alone may suffice to render high levels of resistance, it seems clear that the occurrence of both functional genes is necessary for the full toxicity of Cry1A proteins [20,23]. Although the binding of Cry1A proteins to the $\mathrm{ABCC} 2$ transporter has never been directly shown, it is thought that the $\mathrm{ABCC} 2$ transporter transiently binds the Cry oligomer and mediates its insertion from the APN or ALP receptors to the membrane [24].

In a previous work we have reported an S. exigua strain (Xen-R) with high levels (>1,000-fold) of resistance to a $B$. thuringiensis-based pesticide, Xentari ${ }^{\mathrm{Tu}}$ [25]. Expression of about 600 midgut genes was analyzed by DNA-macroarray in order to find differences in midgut gene expression between susceptible and resistant insects. Among the differentially expressed genes, repat and arylphorin were identified and their increased expression was correlated with $B$. thuringiensis resistance. We also found overlap among genes that were constitutively over-expressed in resistant insects with genes that were up-regulated in susceptible insects after exposure to Xentari ${ }^{\mathrm{Tm}}$, suggesting a permanent activation of the response to Xentari ${ }^{\text {Tx }}$ in resistant insects. However, we could not determine the exact resistant gene or genes and the molecular mechanism responsible of the high levels of resistance to $B$. thuringiensis in these insects.

In the present paper we used bulk segregant analysis (BSA) based on high-throughput sequencing methodologies (also known as 'next generation sequencing' or NGS) $[26,27]$ to identify regions in the $S$. exigua genome containing loci for major resistance genes in Xen-R strain [25]. The results reveal two $A B C C$ genes $(A B B C 2$ and $A B B C 3$ ) involved in the mode of action of $B$. thuringiensis toxins and a mutation in one of them $(A B B C 2)$ as responsible for the resistance of $S$. exigua to a $B$. thuringiensis commercial product and to its main active ingredients, $\mathrm{Cry} 1 \mathrm{Ca}$ and $\mathrm{Cry} 1 \mathrm{~A}$ toxins. The current results expand the role of the $\mathrm{ABCC} 2$ transporter in $B$. thuringiensis resistance beyond the Cry1A family of proteins to include Cry1Ca.

\section{Results}

Construction of backcross families for resistance mapping Mapping of resistance was approached by mixing the resistant and susceptible genomes followed by selection for resistance after one round of backcrosses. At the concentration of the Xentari ${ }^{\text {in }}$ product used, Xen-R showed incomplete resistance because $65 \%$ of the larvae did not survive the treatment. The same treatment killed $100 \%$ of FRA and F1 larvae, indicating that resistance was completely recessive at the diagnostic concentration. After crossing F1 and Xen-R adults and selection with the discriminant concentration of the Xentari ${ }^{\text {tw }}$ product, three families resulting from independent backcrosses were randomly selected for the BSA. Mortality in the treated samples was $87 \%$ for $\mathrm{BC} 1,89 \%$ for $\mathrm{BC} 3$ and $84 \%$ for $\mathrm{BC} 4$. Considering that the baseline mortality for Xen- $\mathrm{R}$ was $65 \%$, the mortality in the three backcross (BC) families is in good agreement with resistance being due to one major locus. Survivors from the three BC families were pooled (Sel-BC sample) and used for the BSA.

\section{New generation sequencing, assembly and mapping}

Parental samples were differentially tagged and sequenced in a single Hi-Seq2000 paired-end (PE) line and Sel-BC in a second line. A summary of the sequencing and assembling process is reported in Table 1. These reads (GenBank SRA accession: SRS514057, SRS514097, and SRS514098), along with the 445,524 sequences from the 454-sequencing and the previously published 6,212 Sanger sequences [28], were assembled using Trinity, yielding a total of 138,989 
Table 1 NGS results for the different samples and transcriptome statistics

\begin{tabular}{lccc}
\hline \multicolumn{1}{c}{ Sample } & Raw reads & Cleaned reads & \% mapped sequences \\
\hline Xen-R & $179,215,722$ & $168,518,208$ & 88.57 \\
FRA & $200,970,866$ & $187,779,324$ & 88.19 \\
BC-sel & $388,370,500$ & $360,354,916$ & 87.27 \\
$\quad$ Transcriptome & Non-filtered & Filtered & 96,676 \\
Unigenes & 138,989 & 54,478 \\
Gene clusters & 85,811 & 2,016 \\
N50 & 1,781 & 109 \\
Size (Mb) & 119 & 10,421 \\
Drosophila orthologs & - & 15,116 & \\
Silkworm orthologs & - &
\end{tabular}

NGS, next generation sequencing.

unigenes and 85,811 gene clusters with an average length of $881 \mathrm{bp}$, with a total length $119 \mathrm{Mb}$. These unigenes were filtered to remove small, non-highly expressed anonymous unigenes. Finally, 96,676 unigenes and 54,478 gene clusters were kept, with an average size of $1,124.25$ and a total length of $109 \mathrm{Mb}$ (GenBank BioProject 219058). These unigenes were compared using bi-directional Blast search with Bombyx and Drosophila proteins. For 10,421 and
15,116 unigenes, orthologs were identified in Drosophila and silkworm, respectively (Table 1, and Additional file 1). All reads were mapped against a filtered reference transcriptome built with the longest unigene of each gene cluster. The proportion of the total sequences which could be properly mapped was $87.27 \%, 88.19 \%$ and $88.57 \%$ from Sel-BC, FRA and Xen-R, respectively. The average coverage was $763.9 x$.

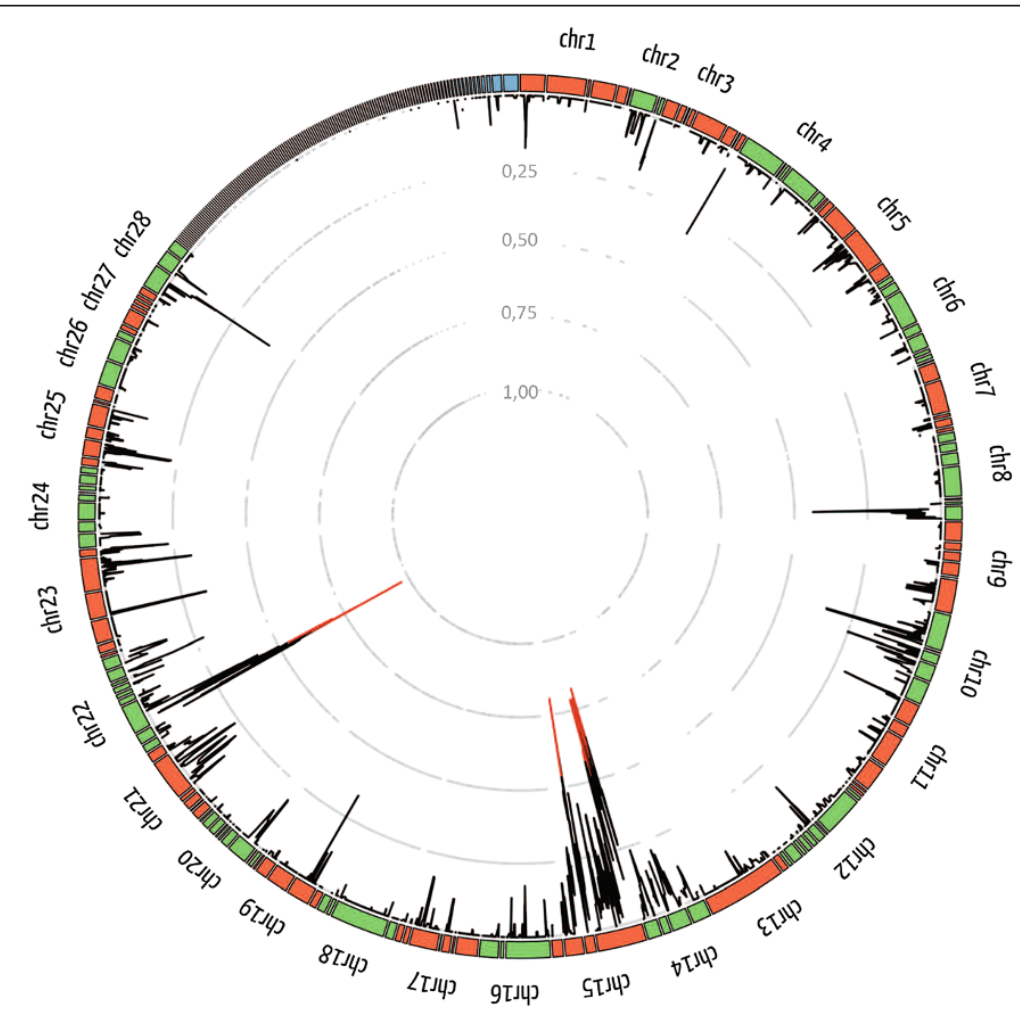

Figure 1 Schematic representation of the BSA index for the SNPs in the S. exigua unigenes with orthologs into the silkworm genome. Each data point (from 0 to 1 ) is the average index for three consecutive orthologs calculated using overlapping rolling-windows (BSA index for each unigene individually is provided in Additional file 3). Average index $>0.60$ are painted in red. BSA, bulk segregant analysis; SNPS, single nucleotide polymorphism. 


\section{Bulk segregant analysis}

Using Varscan, 437,815 single nucleotide polymorphisms (SNPs) and 80,246 indels were identified [see Additional file 2]. To select unigenes with a biased allele distribution in the Sel-BC sample, the following index was calculated: ratio of SNPs with the Xen-R allele fixed in Sel-BC (frequency higher than 0.95) against the total number of SNPs. This index ranged from 0 to 1 . Unigenes with an index close to 1 had a bias towards the allele present in the Xen-R parental. This index was plotted along with the Bombyx genome (Figure 1) by using the position of the respective Bombyx orthologs. A total of 978 unigenes [see Additional file 3]. With a silkworm ortholog were available. Two wide Bombyx genomic regions with a high bias towards the resistant allele were detected: a wider region in chromosome 15 and another smaller region in chromosome 22 . The region in chromosome 15 spanned from 64,363 to $3,068,277$ of nscaf 2888 scaffold and contained homologs to 64 S. exigua unigenes. The region in chromosome 22 spread from 67,364 to $1,716,412$ of nscaf1681 scaffold and contained homologs to $42 \mathrm{~S}$. exigua unigenes.

Detailed analysis of the chromosome 22 region did not reveal genes potentially involved in the mode of action of $B$. thuringiensis or other entomopathogens. Moreover, we could not identify any SNPs associated with Sel-BC or Xen-R insects having a major effect (for example, nonsense mutation) on the codified proteins when compared to the alleles in FRA insects.

Chromosomal regions from several insect species homologous to a region in chromosome 15 in $B$. mori have been previously associated with resistance to $B$. thuringiensis Cry1A toxins [20-22]. Such a B. mori region contains several members of the $A B C C$ family. Detailed analysis of unigenes from $S$. exigua in that region identified three $A B C C$ genes, which we named $A B C C 1, A B C C 2$ and $A B C C 3$ according to a phylogenetic analysis with representative members of $\mathrm{ABC}$ transporter genes from other Lepidoptera and Coleoptera (Figure 2). The S. exigua $A B C C 2$ and $A B B C 3$ genes codify for a 12-transmembrane domain protein [see Additional file 4: Figure S1]. Although our transcriptome did not contain the complete $A B C C 1$ unigene sequence, comparison with other $A B C C 1$ genes suggests that it codifies for a protein with a topology similar to that of other ABCC1 transporters. Allelic comparison of unigenes in that region revealed a major mutation in the $A B C C 2$ gene: a deletion of 246 nucleotides (82 amino acids) in the unigene from the Xen-R and Sel-BC samples, but not from the FRA sample. Despite the high coverage for that gene in the Sel-BC sample, no single read was observed mapping into the deleted region. The deleted region included a fragment of the predicted ATP binding

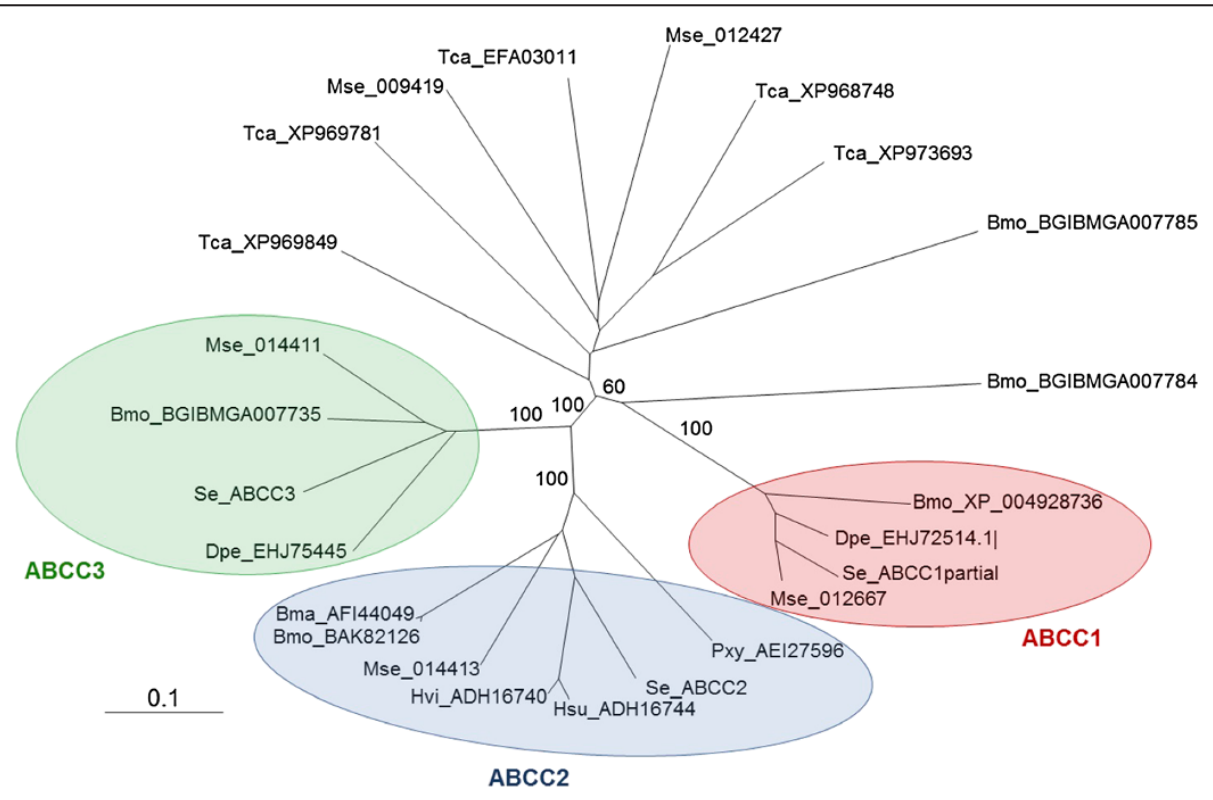

Figure 2 Phylogenetic analysis and ortholog asignment of S. exigua ABCC transporters. Neighbor-joining consensus tree of representative members of ABC transporters from Lepidoptera and Tribolium castaneum (Coleoptera). Nomenclature for each member is based on the name of the species (Bmo: Bombyx mori; Se: Spodoptera exigua; Dpe: Danaus plexippus; Bma: Bombyx mandarina; Hvi: Heliothis virescens; Hsu: Heliothis subflexa; Mse: manduca sexta; Tca: Tribolium castaneum) followed by their accession number from the National Center for Biotechnology Information (NCBI), Silkdb and Manduca Base (Agripest) databases. Sequences were selected based on their homology to the ABCC1-3 transporters from the linkage region in B. mori. Some homologs in T. cataneum were selected as a kind of outgroup. For the sake of clarity bootstrap values are only reported for the branches identifying the main ABCC subgroups. NCBI, National Center for Biotechnology Information. 
domain 2 in the hypothetical protein (Figure 3C). Further analysis of the genomic region revealed a deletion of about 500 nucleotides extending over two exons (Figure 3).

Based on these results, we decided to focus on the possible function of the $\mathrm{ABCC} 2$ and $\mathrm{ABCC} 3$ proteins, especially on their role in the susceptibility to $B$. thuringiensis toxins and the effect of the ABCC2 mutation on the binding of CrylCa toxin to the insect midgut.

\section{Expression profiles of SeABCC2 and SeABCC3 genes in \\ S. exigua}

Gene expression of $\mathrm{SeABCC} 2$ and $\mathrm{SeABCC} 3$ was analyzed by reverse transcriptase-polymerase chain reaction (RT-PCR) in different developmental stages of $S$. exigua and in different tissues of fifth instar larvae. SeABCC2 and SeABCC3 were expressed in all larval instars and in the adult stage although at early stages SeABCC2 was apparently more strongly expressed than $\mathrm{SeABBC3}$ (Figure 4A). Regarding tissue distribution (Figure 4B), SeABCC2 was highly expressed in the gut and hemocytes; in addition, the sample from the fat body gave a very faint amplification band. SeABCC3 was also highly expressed in the gut and hemocytes and faint amplification bands were obtained in samples from the fat body and nerve, but not from the salivary glands.
Effect of SeABCC2 and SeABCC3 suppression on the susceptibility of S. exigua to Cry1Ac and Cry1Ca

To study the role of these proteins in the susceptibility of $S$. exigua to $B$. thuringiensis toxins, $S e A B C C$ genes were silenced by RNA interference (RNAi) and the suppressed larvae were tested for their susceptibility to two different Cry1 toxins. Prior to performing bioassays with double-stranded RNA (dsRNA)-treated larvae, the susceptibility of non-treated S. exigua third instar larvae to Cry1Ac and Cry1Ca protoxins was determined under our experimental conditions. As expected, Cry1Ca was significantly more toxic than Cry1Ac, with $\mathrm{LC}_{50}$ values of 0.24 and $4.8 \mu \mathrm{g} / \mathrm{ml}$, respectively. The toxin concentrations that yielded mortality between $90 \%$ and $100 \%$ were 10 and $1 \mu \mathrm{g} / \mathrm{cm}^{2}$ for Cry1Ac and Cry1Ca, respectively (Figure 4C). These toxin concentrations were chosen for subsequent experiments with dsRNA.

Expression of $\mathrm{SeABCC} 2$ and SeABCC3 started to decrease after 12 hours of dsDNA ingestion, but the suppression was more drastic after 48 hours and lasted at least up to 72 hours in both cases (Figure 4D-E). Crosssuppression between the two genes was discarded by estimation of $\mathrm{SeABCC} 2$ expression in ds $\mathrm{SeABCC} 3$-treated insects and vice versa (Figure $4 \mathrm{D}-\mathrm{E})$. When $S$. exigua larvae were treated with either ds $S e A B C C 2$ or ds $S e A B C C 3$ and then exposed to $10 \mu \mathrm{g} / \mathrm{cm}^{2}$ of Cry1Ac or $1 \mu \mathrm{g} / \mathrm{cm}^{2}$

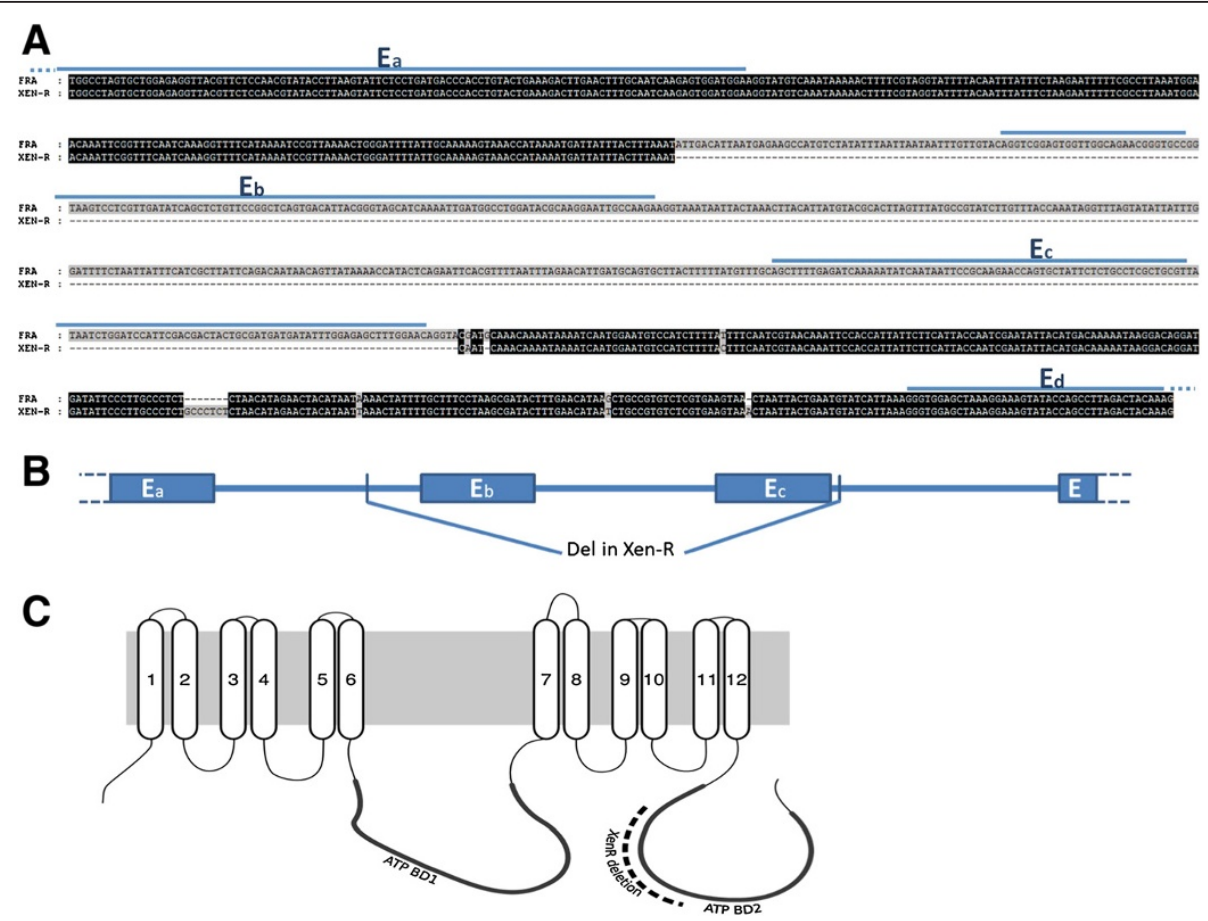

Figure 3 Localization of the deletion in resistant insects into the $A B C C 2$ gene genomic region $(A)$ schematically represented at the genomic region (B) and on the hypothetical protein $(\mathbf{C})$. Sequences were obtained by PCR amplification of the reported region using genomic DNA from the Xen-R and FRA strains. 'E' labels are indicative of the predicted exons in the reported region. The dashed line indicates the deletion in the Xen- $R$ insects. PCR, polymerase chain reaction. 


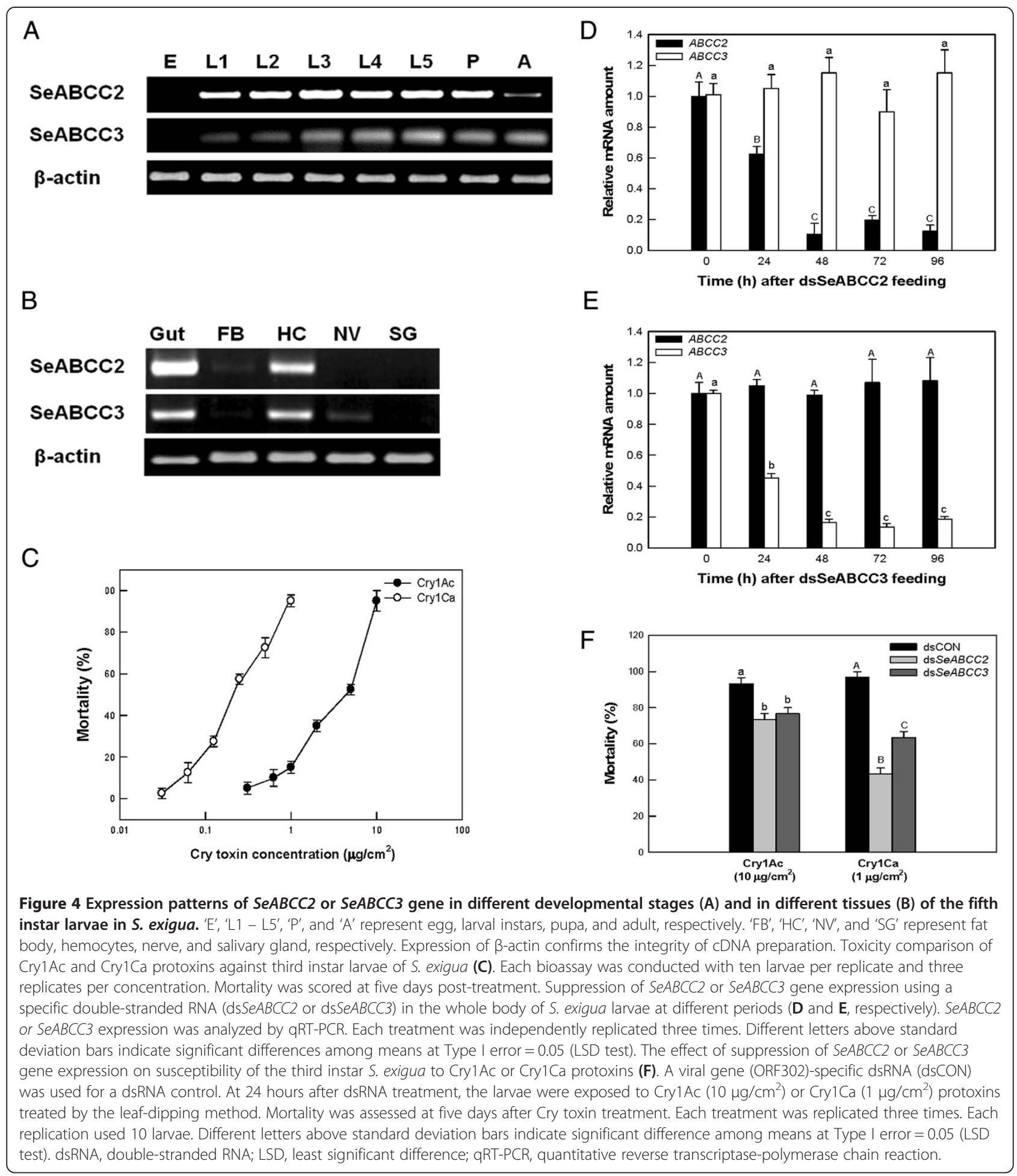

of Cry1Ca, they showed a significant decrease in susceptibility to these two toxins (Figure 4F). In particular, silencing of SeABCC2 highly decreased Cry1Ca toxicity to $S$. exigua compared with silencing of SeABCC3. Under these conditions, control larvae suffered about $92 \%$ and 95\% larval mortality to Cry1Ac or Cry1Ca, respectively.
Binding of Cry1Ca to brush border membrane vesicles from resistant and susceptible larvae

Since mutations in the ABCC2 transporters have been proposed to confer resistance to insects from different species that lacked binding of one or more Cry1A proteins [20,21] binding of ${ }^{125}$ I-labeled Cry1Ca was tested 
in susceptible and resistant insects to see whether binding was altered in the latter (Figure 5). Competition binding curves indicated that resistant insects had a high contribution of non-specific binding (the binding that cannot be displaced with high concentrations of competitor) to the total binding (Figure 5A). The equilibrium binding parameters did not differ significantly between the two types of insects and the only significant differences were found in the concentration of binding sites (Table 2). Specific binding of Cry toxins to their membrane receptors consists of a reversible binding component and an irreversible binding component associated with the toxin insertion into the membrane [29]. To search for additional possible differences in binding, an experiment was designed to dissect the total specific binding into its reversible and irreversible components. The results showed a significant decrease in the irreversible component of the specific binding in resistant insects as compared with susceptible insects (Figure 5B). However, the reversible component was similar in both cases.

\section{Fitness-cost associated with the silencing of SeABCC2 or SeABCC3 expression}

The effect of silencing of either $\mathrm{SeABCC} 2$ or $\mathrm{SeABCC} 3$ on the fitness of the insects was also measured. Reduction in the expression level of both genes had a statistically significant influence on both pupation and adult emergence. Feeding dsRNA specific to either $\operatorname{SeABCC} 2$ or $\mathrm{SeABCC} 3$ reduced the percentage of pupation to $70 \%$ and $81 \%$, respectively (Figure $6 \mathrm{~A}$ ) and the percentage of adult emergence to $72 \%$ and $68 \%$, respectively (Figure 6D). Treatment of dsSeABCC2 also had a significant effect on the pupal weight, although that of dsSeABCC3 did not (measured at the second day of pupal stage) (Figure 6B). In contrast, none of the treatments had a significant effect
Table 2 Equilibrium dissociation constant $\left(K_{d}\right)$ and concentration of binding sites $\left(R_{t}\right)$ of Cry1Ca binding to BBMV from Xentari ${ }^{\mathrm{TM}}$ susceptible (FRA) and resistant (Xen-R) S. exigua larvae

\begin{tabular}{|c|c|c|}
\hline \multirow[t]{2}{*}{ Colony } & \multicolumn{2}{|c|}{ Mean $\pm \mathrm{SEM}^{a}$} \\
\hline & $K_{d}(\mathrm{nM})$ & $R_{t}(\mathrm{pmol} / \mathrm{mg})$ \\
\hline FRA & $14 \pm 2$ & $5.9 \pm 0.6$ \\
\hline Xen-R & $28 \pm 13$ & $2.85 \pm 1.13$ \\
\hline
\end{tabular}

${ }^{a}$ From two independent replicates. BBMV, brush border membrane vesicles; SEM, standard error of the mean.

on the duration of the pupal stage, which in all cases took five to six days from the first day of pupation till adult emergence (Figure 6C).

\section{Overexpression of arylphorin and repat5 genes induced by SeABCC2 and SeABCC3 suppression}

Since both arylphorin and repat5 have been reported to be overexpressed in the Xen-R insects [25], it was of interest to determine whether the silencing of SeABCC2 or $S e A B C C 3$ could have an effect on the expression of these genes. The results show, in agreement with previous reports, that when either the $\mathrm{SeABCC} 2$ or $\mathrm{SeABCC} 3$ gene is silenced, both arylphorin and repat5 genes increased their expression as compared with that of the controls [see Additional file 5: Figure S2].

\section{Discussion}

Forward genetics has been useful in shedding light on new resistance mechanisms to Cry1A proteins in insects. Relatively recently, the role of the ABCC2 transporter has been made evident in the mode of action of Cry1A proteins through linking resistance to mutations in this membrane protein in four different insect species [24]. We have successfully adapted standard BSA procedure to our particular conditions: 1) since we could not easily
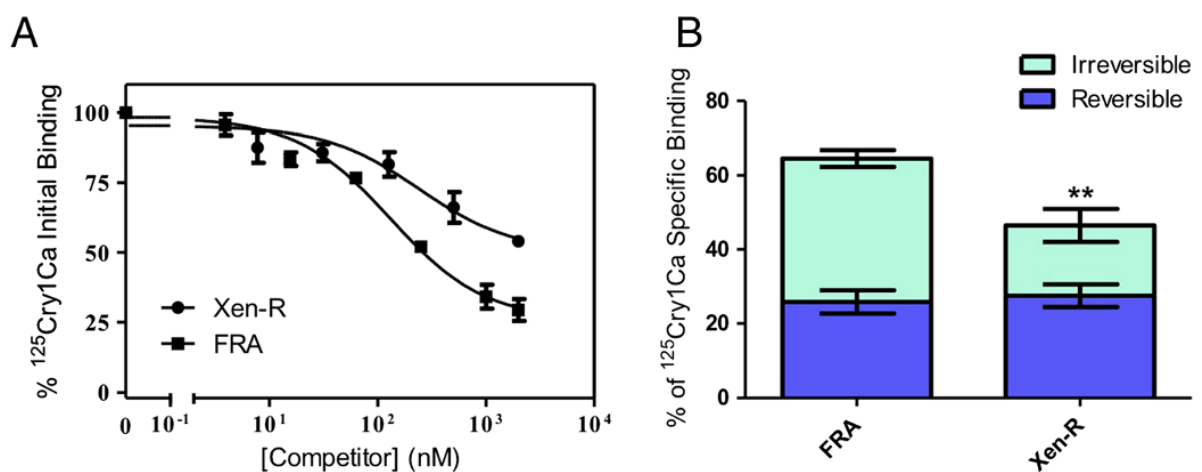

Figure 5 Binding of ${ }^{125}$ I-labeled Cry1Ca to S. exigua BBMV. (A) Homologous competition. ${ }^{125}$-labeled Cry1C was incubated with BBMV from susceptible (FRA) or resistant (Xen-R) insects in the presence of increasing concentrations of unlabeled Cry1C toxin. (B) Dissection of total binding into their reversible and irreversible components. Contribution of both components to the binding of ${ }^{125}$-labeled Cry 1 Ca to BBMV from susceptible and resistant insects were compared. T-test ( $P=0.7244$ for the reversible component) $(P=0.0170$ for the irreversible component). BBMV, brush border membrane vesicles. 

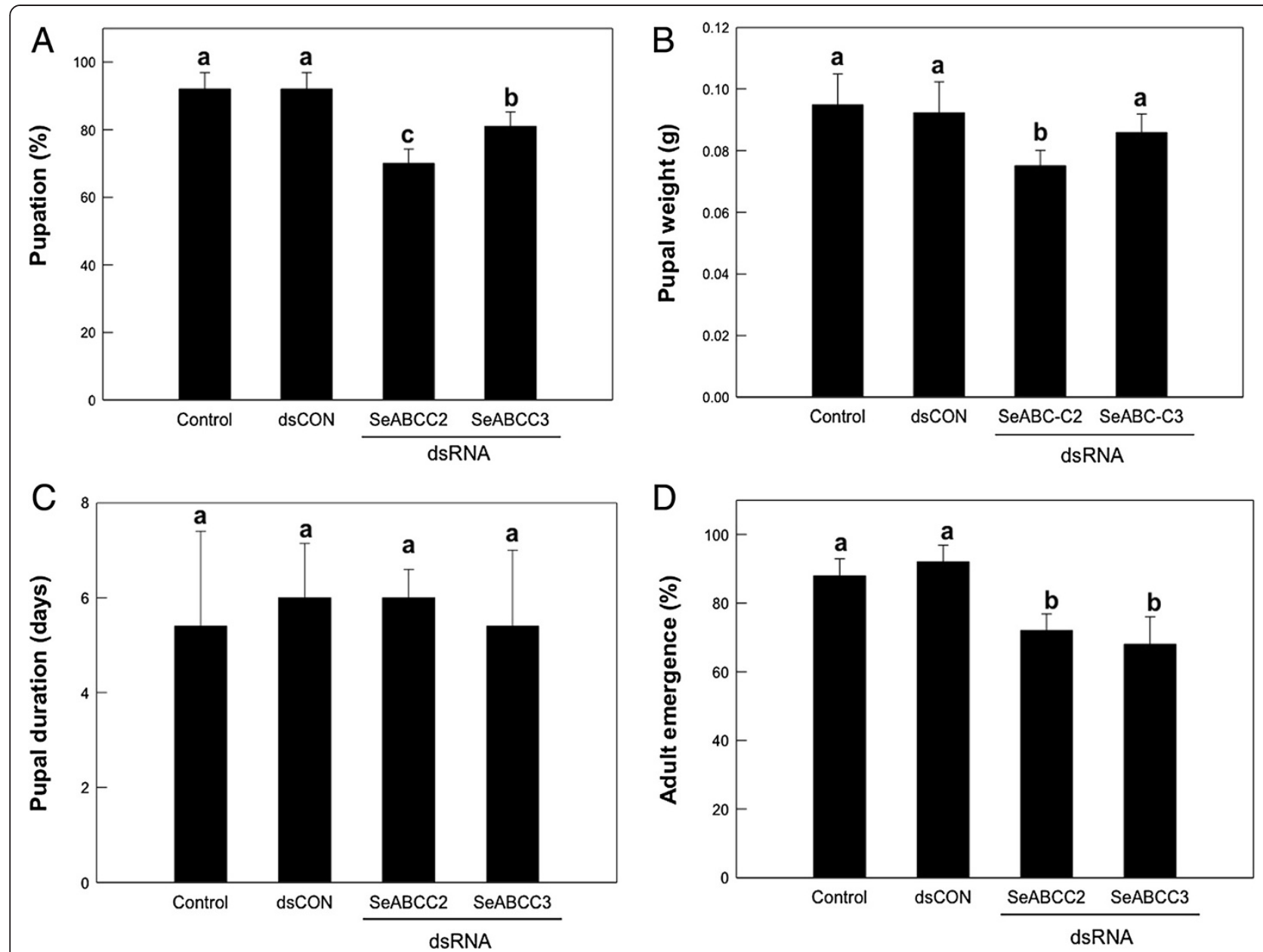

Figure 6 Effect of suppression of SeABCC2 or SeABCC3 gene expression on pupation (A, B, and C) and adult emergence (D) of S. exigua. The expression of SeABCC2 or SeABCC3 gene was suppressed by feeding dsSeABCC2 or dsSeABCC3 to newly molted second instar larvae. A viral gene (ORF302)-specific dsRNA (dsCON) was used for a dsRNA control. Each treatment was replicated three times. (A) Pupation, (B) pupal weight, (C) pupal duration and (D) adult emergence after dsRNA feeding were measured. Each replicate used 10 larvae. Different letters above standard deviation bars indicate significant differences among means at Type I error $=0.05$ (LSD test). dsRNA, double-stranded RNA, LSD, least significant difference.

discriminate susceptible insects in the $\mathrm{BC}$ offsprings we have only used one of the bulk extremes (the resistant insects). As a consequence, evidence of linkage to resistance was not deduced by the comparison of the frequency of the markers in the two bulks, but by comparing their frequency deviation from the expected $50 \%$ and their deduced genomic localization. 2) Due to the absence of genomic information on S. exigua, the resistance gene has been positioned and deduced using the genome of a related Lepidoptera, B. mori. 3) Genetic markers have been discovered by RNA sequencing instead of direct examination of genomic DNA. BSA based on RNA information could introduce a certain bias because the cDNA contribution to the bulk can be allele specific. To prevent or minimize such a possibility the signal has been detected at the genomic level and not at the gene level, thus averaging out the possible bias present in one particular gene. Our approach using NGS and BSA applied to S. exigua has pinpointed two genomic regions with high segregation distortion that have a high probability of containing genes involved in the resistance to $B$. thuringiensis. BSA has been previously employed for the identification of a pesticide resistance gene [30]; however, as far as we know, this is the first report of successful mapping of insect resistance genes by combining asymmetric BSA with RNA sequencing.

One of these two regions contained three genes coding for $\mathrm{ABC}$ type $\mathrm{C}$ transporters, including the $A B C C 2$ gene along with $A B C C 1$ and $A B C C 3$ genes. The sequences of the $A B C C 2$ and $A B C C 3$ genes coded for 12transmembrane domain proteins. Most interestingly, the $A B C C 2$ allele from the resistant insects contained a deletion that eliminates a cytoplasmic portion of the protein affecting one of the two ATP binding regions, 
making this gene a candidate for the resistance in the Xen- $\mathrm{R}$ colony. The second region, located in chromosome 22, did not reveal genes potentially involved in the mode of action of $B$. thuringiensis, although we cannot discard the presence of additional genes in such a region contributing to the resistance in the Xen-R insects. Alternatively, synteny is not complete in Lepidoptera and it could be possible that both regions are located in the same chromosome in S. exigua.

To determine the role of the $\mathrm{ABCC} 2$ transporter, and that of its closest paralog ABCC3, in the mode of action of Cry1 proteins, their developmental expression and tissue distribution has been studied. They both were expressed in the larval midgut, in agreement with the expected characteristics from membrane proteins that must interact with Cry1 proteins toxic to larvae. However, at early stages of development, when insects are more susceptible to $B$. thuringiensis, the expression levels of ABCC3 are lower than those of $\mathrm{ABCC} 2$, suggesting that the latter may play a more relevant role in the mode of action of $B$. thuringiensis toxins. A more direct approach to the involvement of $\mathrm{ABCC} 2$ and $\mathrm{ABCC} 3$ in the toxicity of Cry proteins was to measure the susceptibility to Cry1Ac and Cry1Ca in larvae where the expression of these two transporters had been decreased by feeding dsRNA. With both toxins, mortality significantly decreased when the expression of either ABCC2 or ABCC3 was reduced. This result shows that both transporters are involved in the toxicity of these two Cry1 proteins and that, in theory, mutations in either one could result in resistance to these two toxins. Since the sequence homology between $\mathrm{ABCC} 2$ and $\mathrm{ABCC} 3$ is higher than $70 \%$, it is likely that both proteins could serve as receptors for Cry1 toxins. ABCC1, although not as similar to $\mathrm{ABCC} 2$ as $\mathrm{ABCC} 3$, cannot be discarded at this point as also playing a role in the mode of action of $B$. thuringiensis. However, the most direct evidence of the involvement of ABCC transporters in the mode of action of B. thuringiensis toxins in S. exigua is that resistant insects, but not susceptible controls, carried a mutated allele of the $A B C C 2$ gene.

All previous reports relating the $\mathrm{ABCC} 2$ transporter to resistance to Cry1A proteins have found mutations in the $A B C C 2$ gene that affected the extracellular domains in different ways. In $H$. virescens, the mutation consisted of a 22 -bp deletion in exon 2 , which would result in a truncated product of 99 amino acids instead of the 1,339 amino acids in the wild type protein [20]. In P. xylostella, the $A B C C 2$ gene had a 30-bp deletion in exon 20, which was predicted to remove the final transmembrane domain with the result of positioning the $\mathrm{C}$-terminal end of the protein in the extracellular space instead of its natural location inside the cell [21]. In B. mori, the mutation added an extra tyrosine residue in the second extracellular loop of the ABCC2 transporter [22]. So far, the mutation in the
$A B C C 2$ gene conferring resistance in $T . n i$ has not yet been elucidated [21]. Binding studies with the above resistant colonies showed that insects with the ABCC2 mutation lacked binding of Cry1Ab and Cry1Ac in the case of $H$. virescens and P. xylostella [20,31]. The same lack of binding of these two toxins was found in the T. ni resistant colony [32]. However, no apparent alteration of Cry1Ab binding (Cry1Ac was not tested) was found in the B. mori resistant insects as compared to susceptible controls [22]. As has been hypothesized elsewhere [24], it is very likely that the extra tyrosine residue in the extracellular loop does not prevent binding of Cry1Ab, although it could confer resistance by altering the transporter function and decreasing the probability of the toxin being drawn into the membrane.

The mutation we have found in the S. exigua resistant insects is the first reported mutation that does not affect, directly or indirectly, the extracellular ABCC2 domains, but affects the intracellular C-terminal part of the protein, which contains the second ATP binding domain. If the above model of the involvement of the ABCC2 transporter in the mode of action of Cry1 toxins is correct, we should not expect any decrease in toxin binding since the extracellular domains of the protein are not altered, and the intracellular deletion does not seem to appreciably affect the conformation of the rest of the protein. Similarly to B. mori, resistance would be conferred by altering the transporter function affecting its role in inserting the toxin into the membrane [24]. Our binding data completely agree with this hypothesis. First, no significant difference was found regarding the affinity of the toxin to bind BBMV, and only a small difference was found between resistant and susceptible insects regarding the concentration of binding sites. Second, alteration of the transporter ability to draw the toxin into the membrane would specifically affect the irreversible component of binding, and this is precisely what our results indicate. The involvement of the $\mathrm{ABCC} 2$ transporter in the resistance to $B$. thuringiensis in $S$. exigua adds a new species in which the role of this gene in resistance to Cry proteins has been demonstrated.

Silencing of ABCC2 and ABCC3, in addition to allowing us to confirm the role of these receptors in the mode of action of $B$. thuringiensis, has enabled the study of the fitness cost associated with the absence of these proteins. Although dsRNA feeding could not achieve complete knock-out of gene expression to emulate a resistance gene, partial silencing revealed clear effects on insect fitness. Fitness cost has been associated with resistance in most of the $B$. thuringiensis resistant strains [33]. According to our results, field selection of ABCrelated resistance alleles can be counteracted by the reduced fitness of resistant insects versus susceptible insects in areas not exposed to $B$. thuringiensis products 
(that is, refuges) and, in this way, contribute to delay the development of resistance.

Previous studies on the Xen- $\mathrm{R}$ strain revealed that the insects, in the absence of exposure to $B$. thuringiensis, had a high level of expression of certain genes (arylphorin and repat 5 among them) that are up-regulated in susceptible insects after $B$. thuringiensis intoxication [25]. For this reason we found it interesting to determine whether a decrease in the expression, or a malfunction, of the SeABCC2 or SeABBC3 transporters could trigger the up-regulation of such genes. Our results reveal that silencing of $\mathrm{SeABCC} 2$ or $\mathrm{SeABCC}$, in susceptible insects, induces the expression of arylphorin and repat5. Such a result suggests that higher expression levels of these genes in the Xen- $R$ insects are induced by the mutation in the SeABCC2 receptor. Additionally, up-regulation of these genes in response to $B$. thuringiensis intoxication might be induced by the interaction of the toxins with the ABCC receptors, perhaps because binding of the toxin would probably block their physiological function. Other studies have shown that arylphorin and repat5, as well as other members of the repat superfamily, are induced in response to intoxication with several types of toxins in Spodoptera spp. [34-36]. It would be of interest to check whether other resistant strains with mutations in the ABCC2 transporter overexpress these genes and to explore the possibility of using such a phenotype as a marker to monitor for the presence of $\mathrm{ABC}$-related mutations in the field.

Also worth noting is the fact that the $A B C C 2$ mutation in $S$. exigua apparently confers resistance not only to Cry1A proteins but to Cry1Ca as well. Although Xentari ${ }^{\text {im }}$ contains Cry1A and Cry1Ca as major Cry components [37], S. exigua larvae are susceptible to Cry1Ca but relatively tolerant to Cry1A proteins [38]. Therefore, resistance to Xentari ${ }^{\text {тм }}$ in Xen-R implies resistance to the Cry1Ca key component. Another indirect piece of evidence that mutations in the $\mathrm{ABCC} 2$ transporter may be involved in resistance to Cry1 toxins other than those of the Cry1A family was recently reported in P. xylostella [39]. Cry1A resistant insects with a mutation in the $A B C C 2$ gene were cross-resistant to Cry1Fa and they lacked binding of Cry1A proteins and Cry1Fa to BBMV [39]. In this insect species, it was already known that Cry1Fa shares binding sites with Cry1A proteins [40].

Fifteen $A B C C$ genes have been annotated on the $B$. mori genome $[41,42]$. It would be interesting to test whether additional members of such a family in Lepidoptera, but also in other insect orders, could be involved in modulating the insect susceptibility to Cry1 toxins and also to other groups of toxins, such as Cry2 and Cry3. Examples of membrane proteins that are known to serve as surrogate receptors for a wide variety of Cry proteins are cadherin, APN and ALP. All have been reported to be the binding proteins for quite different Cry toxins, such as Cry1, Cry3, and Cry4 and Cry11, which are active against Lepidoptera, Coleoptera and Diptera, respectively [10,43-48]. It seems that different Cry proteins have found the appropriate insect species, or even insect order, to interact with a same type of surrogate receptor.

\section{Conclusions}

BSA, based on high-throughput transcriptome sequencing, can be applied for genetic mapping in invertebrates. In this study, BSA has contributed to the identification of a novel type of mutation in the ABCC2 transporter conferring high levels of insect resistance to B. thuringiensis. Additional results have expanded the role of the $\mathrm{ABCC} 2$ transporter in $B$. thuringiensis resistance beyond the Cry1A family of proteins to include Cry1Ca and revealed the involvement of different members of the ABCC family in the mode of action of $B$. thuringiensis and in the fitness-cost associated with the resistance to $B$. thuringiensis.

\section{Methods}

\section{Source of Cry toxins}

B. thuringiensis Cry toxins, Cry1Ac and Cry1Ca, were obtained from recombinant Escherichia coli XL-1 strains (kindly supplied by Dr. Ruud de Maagd, Plant Research International, Wageningen, The Netherlands). Protein production, solubilization and trypsin activation was performed as described earlier [49]. Proteins used for bioassays were in the form of protoxin dissolved in carbonate buffer $(0.1 \mathrm{M}$ $\mathrm{Na}_{2} \mathrm{CO}_{3}, 0.01 \mathrm{M}$ ethylenediaminetetraacetic acid (EDTA), $0.17 \mathrm{M} \mathrm{NaCl}, \mathrm{pH}$ 10.5). For binding assays, Cry1Ca was further purified by anion-exchange chromatography followed by gel filtration on a Superdex-75 column containing $1 \mathrm{mM}$ dithiothreitol (DTT) according to published procedures $[50,51]$, to remove the adsorbed toxin fragments that could interfere in the radiolabeling of the toxin. Protein concentration was measured using the Coomassie protein assay reagent (Bio-Rad, Hercules, CA, USA) with bovine serum albumin (Sigma-Aldrich, Tres Cantos, Spain) as the standard.

\section{Source of insects and genetic crosses}

For genetic and binding analyses, two S. exigua laboratory colonies were used. The resistant colony (Xen-R) was highly resistant to the commercial bioinsecticide Xentari ${ }^{\text {тм }}$ (based on B. thuringiensis subsp. aizawai, Valent Biosciences, Libertyville, IL, USA). This colony has been previously described by Hernández-Martínez et al., [25] and the resistance level was maintained with a constant selection protocol in which neonate larvae were reared for five days on an artificial diet containing Xentari ${ }^{\text {тм }}$ [52], at $10 \mathrm{mg}$ per gram of artificial diet. The susceptible control colony (FRA) originated from France and has been maintained for at least 10 years without B. thuringiensis exposure. For 
the functional analysis of $A B C C$ genes, a third $S$. exigua colony (KOR) was established from larvae collected from a field population infesting welsh onion in Andong, Korea. Larvae from all colonies were reared on an artificial diet at $25^{\circ} \mathrm{C}$ and adults were fed with $10 \%$ sucrose. Insects were reared on an artificial diet at $25 \pm 3^{\circ} \mathrm{C}$ with $70 \pm 5 \%$ relative humidity and a photoperiod of 16/8 hours (light/dark).

For resistance mapping, single-pair crosses were performed between females from the Xen- $R$ colony and males from the FRA colony. From the F1 offspring from each family, one male was backcrossed with five Xen- $R$ females. Neonate larvae from the resulting progeny $(\mathrm{BC}$ families) were reared for five days on an artificial diet containing Xentari ${ }^{\mathrm{mx}}(10 \mathrm{mg} / \mathrm{g})$ and then transferred to a normal diet until they reached the fifth instar. Survivors from each $B C$ family were pooled (Sel-BC sample) and used for NGS and BSA. Sel-BC insects must be homozygous for the resistance allele or alleles and it should contain, on average, a $75 \%$ genome background of the parental resistant colony.

\section{RNA extraction and NGS sequencing}

For BSA, three samples were processed: Xen-R, FRA, and Sel-BC. For each sample, about 30 early fifth instar larvae midguts were dissected and used for total RNA isolation using Trizol (Invitrogen, Carlsbad, CA, USA) following the manufacturer's instructions. The quality and quantity of total RNA was determined spectroscopically at 230, 260, and $280 \mathrm{~nm}$. About $20 \mu \mathrm{g}$ of total RNA from each sample was sent to Macrogen Inc (Seoul, Korea) for mRNA isolation and high-throughput sequencing using the Illumina Hi-Seq2000 paired-end technology.

\section{Sequence analysis}

Hi-Seq2000 reads were analyzed using seq_scrumbs [53] to trim bad quality regions. These reads were assembled with Trinity [54] along with the 454-sequencing reads of the previous transcriptome [28]. To keep only the most informative unigenes, a selection of the assembled unigenes was carried out. For a unigene to be finally selected, it should have to be evaluated as positive for any one of the following criteria: having a CDS (Coding DNA sequence), having a Blastx match against Bombyx or Drosophila proteins, being expressed with a level higher than 0.25 RPKM (reads per kilo base per million) or being longer than $500 \mathrm{bp}$.

A SNVs (single nucleotide variants: SNPs and Indels) search was done only on the longest unigene from each defined unigene cluster. The Illumina and 454-sequencing reads were mapped against these reduced unigene sets with bowtie2 [55] and bwa for sequences from the 454sequencing [56]. SNVs were identified with Varscan2 software [57]. Orthologues for each unigene were identified with a bi-directional Blast search comparison against $B$. mori and Drosophila melanogaster protein databases.

\section{Analysis of the genomic region}

The genomic sequence for the $\mathrm{ABCC} 2$ region, which includes the mutation in the Xen-R colony, was obtained. Primers flanking the deleted region were designed based on the mRNA sequence from the FRA colony and used for PCR amplification of the genomic region using total DNA from Xen-R and FRA adults. PCR products for both colonies were cloned in the pGEM-T-easy vector (Invitrogen) and several clones were sequenced and assembled to generate the consensus sequence. At least three independent clones were used for each of the sequenced samples.

\section{Sequence comparison and phylogenetic analysis}

Sequences from the ABCC receptors from other insect species used for phylogenetic analyses were retrieved after Blast-search against different databases: NCBI, Silkdb and Manduca Base (Agripest). For the sake of clarity, only representative genes from selected lepidopteran species and from the coleopteran $T$. castaneum were included in the analysis. Amino acid sequences were aligned using ClustalX with default settings [58] and visualized in GeneDoc [59]. Phylogenetic analyses were performed using the neighborjoining method with 100 bootstraps, using the ClustalX [58] and MEGA5 programs [60]. Phylogenetic trees were visualized with the MEGA5 program. Nucleotide binding domains in the $\mathrm{ABCC}$ receptors were identified by comparison against the $\mathrm{CDD}$ (conserved domain database) at NCBI [61]. Transmembrane regions in the protein were predicted using TOPCONS online software [62].

\section{Semiquantitative and quantitative RT-PCR}

Total RNA was extracted from whole bodies of different developmental stages or from different tissues from fifth instar larvae with Trizol (Invitrogen) according to the manufacturer's instructions. Aliquots $(1 \mu \mathrm{g})$ were incubated at $70^{\circ} \mathrm{C}$ for three minutes and then used for synthesizing cDNA using an RT-mix kit (Intron, Seoul, Korea). For semiquantitative RT-PCR, the synthesized single-stranded cDNA was used as a template for PCR amplification with gene-specific primers for SeABCC2 (5'-GAG CCT AAC ATG GCT GAC TAT C-3' and 5'CTG CCT ACA TTT GCG TCT ACT-3') and SeABCC3 (5'-TCT ATA CGA CCG CTC TCT TAC C-3' and 5'CAC CCT GCA CAC CTT CTT AT-3') with 35 cycles under the following conditions: 20 seconds at $94^{\circ} \mathrm{C}$ for denaturation, 50 seconds at $55^{\circ} \mathrm{C}$ for annealing, and one minute at $72^{\circ} \mathrm{C}$ for extension. A housekeeping gene, $\beta$ actin, was used as an internal control in each sample for an equivalent of template with actin primers ( $5^{\prime}$-TGG CAC CAC ACC TTCTAC-3' and 5'-CAT GAT CTG 
GGT CAT CTT CT-3') with 35 cycles under the following conditions: 20 seconds at $94^{\circ} \mathrm{C}$ for denaturation, 20 seconds at $50^{\circ} \mathrm{C}$ for annealing, and one minute at $72^{\circ} \mathrm{C}$ for extension.

The mRNA expression level of SeABCC2 and SeABCC3 genes was further confirmed by quantitative RT-PCR (qRT-PCR). qRT-PCR was performed with an Applied Biosystems 7500 real-time PCR system (Applied Biosystems, Foster City, CA, USA) using SYBR ${ }^{\circ}$ Green Realtime PCR master mix (Toyobo, Osaka, Japan) according to the manufacturer's instructions with the gene-specific primers described above. Template cDNA from 48 hour dsRNAtreated third instar larvae (see below) was used for the qRT-PCR reaction. After a hot start at $94^{\circ} \mathrm{C}$ for 10 minutes, qRT-PCR was performed with 40 cycles of one minute at $94^{\circ} \mathrm{C}, 30$ seconds at $55^{\circ} \mathrm{C}$ and 40 seconds at $72^{\circ} \mathrm{C}$. The housekeeping gene $\beta$-actin was used as a control with the primers described above. Each condition was independently replicated three times. Quantitative analysis of SeABCC2 and SeABCC3 expression was done using the comparative $\mathrm{C}_{\mathrm{T}}\left(\Delta \Delta \mathrm{C}_{\mathrm{T}}\right)$ method [63].

\section{Preparation and delivery of RNA interference (RNAi) of $\mathrm{SeABCC} 2$ and SeABCC3}

Template cDNA was amplified with the following primers containing T7 RNA polymerase promoter sequence for SeABCC2 (5'-TAA TAC GAC TCA CTA TAG GGA GAG GAG CCT AAC ATG GCT GAC TAT C-3' and 5'TAA TAC GAC TCA CTA TAG GGA GAG CTG CCT ACA TTT GCG TCT ACT-3') and SeABCC3 (5' -TAA TAC GAC TCA CTA TAG GGA GAG TCT ATA CGA CCG CTC TCT TAC C-3' and 5' -TAA TAC GAC TCA CTA TAG GGA GAG CAC CCT GCA CAC CTT CTT AT-3'). Sequence identity between $\mathrm{SeABCC} 2$ and $\mathrm{SeABCC} 3$ at the region used for dsRNA was less than $65 \%$. The PCR products were used to prepare dsRNA using the MEGA Script RNAi kit according to the manufacturer's instructions (Ambion, Austin, TX, USA). The synthesized RNAs were annealed at $37^{\circ} \mathrm{C}$ for four hours and then left at $70^{\circ} \mathrm{C}$ for five minutes. Before dsRNA feeding, the solution was prepared by mixing a transfection reagent, Metafectene PRO (Biontex, Plannegg, Germany), with dsRNA in 1:1 $(\mathrm{v} / \mathrm{v})$ ratio and then incubated for 20 minutes at $25^{\circ} \mathrm{C}$.

For the dsRNA feeding assays, cabbage $(1 \times 1 \mathrm{~cm})$ was used as a carrier by applying $4 \mu \mathrm{L}$ of the dsRNA (150 ng total) solution on a piece of cabbage leaf. Second instar larvae were starved for six hours before being allowed to feed on cabbage treated with dsRNA for four hours at $25^{\circ} \mathrm{C}$. Then, fresh artificial diet was supplied to the larvae to continue development. To determine the effect of the transfection reagent on S. exigua larvae, a control bioassay was performed using only $4 \mu \mathrm{L}$ of Metafectene PRO solution on cabbage leaf. Metafectene PRO does not affect the development and mortality of control larvae (data not shown). Knockdown of $\mathrm{SeABCC} 2$ and $\mathrm{SeABCC} 3$ gene expression was evaluated by RT-PCR at selected periods up to 96 hours post feeding. A viral gene, CpBV-ORF302, was used as a negative control for RNAi [64].

\section{Bioassays}

S. exigua third instar larvae were used in bioassays with Cry1Ac and CrylCa proteins. For the concentration response bioassays, the concentrations tested for Cry1Ac were $0.625,1.25,2.5,5$ and $10 \mu \mathrm{g} / \mathrm{cm}^{2}$, while for Cry1Ca, the concentrations tested were $0.062,0.125,0.25,0.5$ and $1 \mu \mathrm{g} / \mathrm{cm}^{2}$. Cry1 toxins were serially diluted with sterile deionized water and then overlaid on the piece of cabbage leaf and air-dried for 20 minutes. Each bioassay was conducted with 10 larvae per replicate and three replicates per concentration. Mortality was scored at five days posttreatment. $\mathrm{LC}_{50}$ values were calculated by Probit analysis using the EPA Probit Analysis program, version 1.5 (US Environmental Protection Agency, Cincinnati, OH, USA).

For dsRNA bioassays, $S$. exigua second instar larvae were fed dsRNA specific to $S e A B C C 2$ and $S e A B C C 3$ as described above for 24 hours. Then, larvae were exposed to Cry1Ac or Cry1Ca protoxins for five days using the same method as before. Control larvae were treated with $4 \mu \mathrm{L}$ of control dsRNA (dsCON). Each treatment was replicated three times with ten larvae per replicate. Means and variances of treatments were analyzed in one-way analysis of variance (ANOVA) by PROC GLM of SAS program (SAS Institute, 1989). The means were compared by the LSD test at Type I error $=0.05$.

\section{Binding assays}

Last-instar larvae from the susceptible (FRA) and the resistant (Xen-R) colonies were dissected and the bolusfree midguts were preserved at $-80^{\circ} \mathrm{C}$ until required. BBMVs were prepared by the differential magnesium precipitation method [65], frozen in liquid nitrogen, and stored at $-80^{\circ} \mathrm{C}$. The total protein concentration of the BBMV preparations was determined by the Bradford method using bovine serum albumin as standard.

Chromatography-purified Cry1Ca was labeled using the chloramine-T method [66]. Cry1Ca $(25 \mu \mathrm{g})$ was mixed with $0.5 \mathrm{mCi}$ of ${ }^{125} \mathrm{NaI}$ (PerkinElmer, Boston, MA, USA), chloramine $\mathrm{T}$ was added to be at $6 \mathrm{mM}$ final concentration. After 45 seconds of incubation at room temperature, the reaction was stopped by adding potassium metabisulfite followed by non-radioactive NaI. The specific activity of the ${ }^{125} \mathrm{I}$-Cry1Ca was $0.73 \mu \mathrm{Ci} / \mu \mathrm{g}$.

All binding assays were performed at room temperature in a final volume of $0.1 \mathrm{ml}$ in binding buffer (phosphate buffer saline: $\mathrm{pH} 7.4$ phosphate-buffered saline (PBS), supplemented with $0.1 \%$ bovine serum albumin). For the determination of the optimal concentration of BBMV to be 
used for the binding assays, $1 \mathrm{nM}$ of ${ }^{125} \mathrm{I}$-Cry1Ca was incubated for one hour with increasing concentrations of BBMV (from either FRA or Xen-R insects). The nonspecific binding was determined using an excess of unlabeled toxin.

Competition binding assays were performed by incubating $1 \mathrm{nM}$ of ${ }^{125} \mathrm{I}$-Cry1Ca with $32 \mu \mathrm{g}$ of BBMV and increasing concentrations of unlabeled toxin for one hour. The unbound radio-labeled toxin was washed out and the amount of residual bound ${ }^{125} \mathrm{I}-\mathrm{Cry} 1 \mathrm{Ca}$ was determined using a 2480 WIZARD $^{2}$ (Perkin Elmer, Waltham, MA, USA) gamma counter. The dissociation constant $\left(K_{d}\right)$ and concentration of binding sites $\left(R_{t}\right)$ were calculated using the LIGAND program [67].

To determine the contribution of reversible and irreversible binding to the observed specific binding, three reaction mixtures were prepared with $1 \mathrm{nM}$ of ${ }^{125} \mathrm{I}-\mathrm{Cry} 1 \mathrm{Ca}$ and $30 \mu \mathrm{g}$ of BBMV, and all the samples were incubated for two hours. One sample was used to determine the total binding. In a second sample, used to determine the nonspecific binding, an excess of unlabeled toxin was added at the start of the incubation. To the third sample, which was used to measure the irreversible binding, an excess of unlabeled toxin was added after one hour of incubation and the reaction was allowed to proceed until two hours. The specific binding was calculated by subtracting the radioactivity in the pellet of the second sample from that in sample one and the irreversible binding was calculated by subtracting the radioactivity in the pellet of the second sample from that in the third sample. Therefore, the reversible binding was calculated by subtracting the irreversible binding from the amount of specific binding. Experiments were performed in triplicate and similar results were obtained from two independent batches of BBMV.

\section{Developmental analysis of dsRNA treatment}

RNAi-treated second instar larvae were analyzed for the possible effects on pupation and adult emergence. Metafectene PRO transfection reagent $(4 \mu \mathrm{L})$ without dsRNA was used to feed control larvae. Each treatment was replicated three times with ten larvae per replicate. Pupation success, weight of newly pupated individuals, pupation time at $25^{\circ} \mathrm{C}$ and adult emergence were analyzed.

\section{Expression levels of arylphorin and repat5 genes by RNAi of $\mathrm{SeABCC} 2$ and SeABCC 3 genes}

CDNAs prepared from individuals at 48 hours after ds $S e A B C C 2$, ds $S e A B C C 3$ or dsRNA ${ }^{O R F 302}$ (dsCON) feeding were used for the analysis of arylphorin and repat 5 gene expression by qRT-PCR. After a hot start at $94^{\circ} \mathrm{C}$ for 10 minuts, qRT-PCR amplification was performed as before with gene-specific primers for arylphorin and repat5 [25].

\section{Additional files}

\author{
Additional file 1: S. exigua unigenes with orthologs in $D$. \\ melanogaster and B. mori.
}

Additional file 2: SNVs (single nucleotide variants: SNPs and Indels) from $S$. exigua identified in the BSA studies.

Additional file 3: Unigenes from S. exigua mapping to the B. mori genome and their BSA index.

Additional file 4: Figure S1. Alignment of the predicted amino acid sequences of $A B B C C 2$ and $A B C C 3$ transporters from S. exigua. Blue and orange regions are predicted transmembrane domains for $A B C C 2$ and $A B C C 3$, respectively. The red dotted line localizes the deletion in $A B C C 2$ in resistant insects.

Additional file 5: Figure S2. Overexpression of arylphorin and repat5 genes induced by SeABCC2 or SeABCC3 suppression in third instar S. exigua. The expression of SeABCC2 or SeABCC3 was suppressed in third instar larva by feeding double-stranded RNA (dsSeABCC2 or dsSeABCC3, 150 ng per larva). A viral gene (ORF302)-specific dsRNA (dsCON) was used for a dsRNA control. Expression of $\beta$-actin confirms the integrity of cDNA preparation.

\section{Competing interests}

The authors declare that they have no competing interests.

\section{Authors' contributions}

JB, JC and SH designed the study. YP, RGM, GNC, MC, PZ and SH carried out the experiments. JB, JC, YK, JF and SH analyzed the data. JF and $\mathrm{SH}$ wrote the paper. All authors read and approved the final manuscript.

\section{Acknowledgements}

We want to thank C.S. Hernández-Rodríguez for her comments on binding assays, Ismael Mingarro for his help in determination of ABCC domains and William Moar (Auburn University, Auburn, AL) for his comments on the manuscript and generating the Xen-R colony. This research was partially supported by IPET (Korea Institute of Planning and Evaluation for Technology in Food, Agriculture, Forestry and Fisheries), Ministry of Agriculture, Food and Rural Affairs to YK. Research at the University of Valencia was supported by Generalitat Valenciana (prometeo/2011/044) and Ministry of Science and Innovation (AGL2011-30352-C02-02 and AGL2012-39946-C02-01).

\section{Author details}

'Department of Bioresource Sciences, Andong National University, Andong 760-749, Korea. ${ }^{2}$ Department of Genetics, Universitat de València, Dr Moliner 50, 46100 Burjassot, Spain. ${ }^{3}$ Institute for Conservation \& Improvement of Valentian Agrodiversity (COMAV), Polytechnic University of Valencia, Valencia, Spain.

Received: 28 February 2014 Accepted: 2 June 2014

Published: 9 June 2014

\section{References}

1. Kumar S, Chandra A, Pandey KC: Bacillus thuringiensis (Bt) transgenic crop: an environment friendly insect-pest management strategy. J Environ Biol 2008, 29:641-653.

2. Sanahuja G, Banakar R, Twyman RM, Capell T, Christou P: Bacillus thuringiensis: a century of research, development and commercial applications. Plant Biotechnol J 2011, 9:283-300.

3. Ferré J, Van Rie J, MacIntosh SC: Insecticidal genetically modified crops and insect resistance management (IRM). In Integration of Insect-resistant Genetically Modified Crops within IPM Programs. Edited by Romeis J, Shelton AM, Kennedy GG. Dordrecht: Springer Science and Business Media; 2008:41-85.

4. Tabashnik BE, Brevault T, Carriere $Y$ : Insect resistance to Bt crops: lessons from the first billion acres. Nat Biotechnol 2013, 31:510-521.

5. Sumerford DV, Head GP, Shelton A, Greenplate J, Moar W: Field-evolved resistance: assessing the problem and ways to move forward. J Econ Entomol 2013, 106:1525-1534.

6. Vachon V, Laprade R, Schwartz JL: Current models of the mode of action of Bacillus thuringiensis insecticidal crystal proteins: a critical review. J Invertebr Pathol 2012, 111:1-12. 
7. Pardo-López L, Soberón M, Bravo A: Bacillus thuringiensis insecticidal three-domain Cry toxins: mode of action, insect resistance and consequences for crop protection. FEMS Microbiol Rev 2013, 37:3-22.

8. Rodrigo-Simón A, Caccia S, Ferré J: Bacillus thuringiensis Cry1Ac toxinbinding and pore-forming activity in brush border membrane vesicles prepared from anterior and posterior midgut regions of lepidopteran larvae. Appl Environ Microbiol 2008, 74:1710-1716.

9. Ferré J, Van Rie J: Biochemistry and genetics of insect resistance to Bacillus thuringiensis. Annu Rev Entomol 2002, 47:501-533.

10. Pigott $C R$, Ellar DJ: Role of receptors in Bacillus thuringiensis crystal toxin activity. Microbiol Mol Biol Rev 2007, 71:255-281.

11. Gill M, Ellar D: Transgenic Drosophila reveals a functional in vivo receptor for the Bacillus thuringiensis toxin Cry1 Ac1. Insect Mol Biol 2002, 11:619-625

12. Rajagopal R, Sivakumar S, Agrawal N, Malhotra P, Bhatnagar RK: Silencing of midgut aminopeptidase $\mathrm{N}$ of Spodoptera litura by double-stranded RNA establishes its role as Bacillus thuringiensis toxin receptor. J Biol Chem 2002, 277:46849-46851.

13. Gahan LJ, Gould F, Heckel DG: Identification of a gene associated with Bt resistance in Heliothis virescens. Science 2001, 293:857-860.

14. $\mathrm{XuX}, \mathrm{Yu}, \mathrm{L}, \mathrm{Wu} Y$ : Disruption of a cadherin gene associated with resistance to Cry1Ac \{delta\}-endotoxin of Bacillus thuringiensis in Helicoverpa armigera. Appl Environ Microbiol 2005, 71:948-954.

15. Yang $Y$, Chen $H$, Wu Y, Yang $Y$, Wu S: Mutated cadherin alleles from a field population of Helicoverpa armigera confer resistance to Bacillus thuringiensis toxin Cry1Ac. Appl Environ Microbiol 2007, 73:6939-6944.

16. Morin S, Biggs RW, Sisterson MS, Shriver L, Kirk CE, Higginson D, Holley D, Gahan LJ, Heckel DG, Carriere Y, Dennehy TJ, Brown JK, Tabashnik BE: Three cadherin alleles associated with resistance to Bacillus thuringiensis in pink bollworm. Proc Natl Acad Sci U S A 2003, 100:5004-5009.

17. Herrero S, Gechev T, Bakker PL, Moar WJ, de Maagd RA: Bacillus thuringiensis Cry1Ca-resistant Spodoptera exigua lacks expression of one of four Aminopeptidase N genes. BMC Genomics 2005, 6:96.

18. Yang Y, Zhu YC, Ottea J, Husseneder C, Leonard BR, Abel C, Huang F: Molecular characterization and RNA interference of three midgut aminopeptidase $\mathrm{N}$ isozymes from Bacillus thuringiensis-susceptible and resistant strains of sugarcane borer, Diatraea saccharalis. Insect Biochem Mol Biol 2010, 40:592-603.

19. Tiewsiri K, Wang P: Differential alteration of two aminopeptidases $\mathrm{N}$ associated with resistance to Bacillus thuringiensis toxin Cry1 Ac in cabbage looper. Proc Natl Acad Sci U S A 2011, 108:14037-14042.

20. Gahan $\amalg$, Pauchet $Y$, Vogel $H$, Heckel DG: An ABC transporter mutation is correlated with insect resistance to Bacillus thuringiensis Cry1Ac toxin. PLoS Genet 2010, 6:e1001248

21. Baxter SW, Badenes-Pérez FR, Morrison A, Vogel H, Crickmore N, Kain W, Wang P, Heckel DG, Jiggins CD: Parallel evolution of Bacillus thuringiensis toxin resistance in lepidoptera. Genetics 2011, 189:675-679.

22. Atsumi S, Miyamoto K, Yamamoto K, Narukawa J, Kawai S, Sezutsu H, Kobayashi I, Uchino K, Tamura T, Mita K, Kadono-Okuda K, Wada S, Kanda K, Goldsmith MR, Noda H: Single amino acid mutation in an ATP-binding cassette transporter gene causes resistance to Bt toxin Cry1 Ab in the silkworm, Bombyx mori. Proc Natl Acad Sci U S A 2012, 109:E1591-E1598.

23. Tanaka S, Miyamoto K, Noda H, Jurat-Fuentes JL, Yoshizawa Y, Endo H, Sato R: The ATP-binding cassette transporter subfamily $C$ member 2 in Bombyx mori larvae is a functional receptor for Cry toxins from Bacillus thuringiensis. FEBS J 2013, 280:1782-1794.

24. Heckel DG: Learning the $A B C s$ of Bt: $A B C$ transporters and insect resistance to Bacillus thuringiensis provide clues to a crucial step in toxin mode of action. Pestic Biochem Physiol 2012, 104:103-110.

25. Hernández-Martínez P, Navarro-Cerrillo G, Caccia S, de Maagd RA, Moar WJ, Ferré J, Escriche B, Herrero S: Constitutive activation of the midgut response to Bacillus thuringiensis in Bt resistant Spodoptera exigua. PLoS One 2010, 5:9.

26. Michelmore RW, Paran I, Kesseli RV: Identification of markers linked to disease-resistance genes by bulked segregant analysis: a rapid method to detect markers in specific genomic regions by using segregating populations. Proc Natl Acad Sci U S A 1991, 88:9828-9832.

27. Magwene PM, Willis JH, Kelly JK: The statistics of bulk segregant analysis using next generation sequencing. PLoS Comput Biol 2011, 7:e1002255.

28. Pascual L, Jakubowska AK, Blanca JM, Cañizares J, Ferré J, Gloeckner G, Vogel H, Herrero S: The transcriptome of Spodoptera exigua larvae exposed to different types of microbes. Insect Biochem Mol Biol 2012, 42:557-570.

29. Liang Y, Patel SS, Dean DH: Irreversible binding kinetics of Bacillus thuringiensis CrylA delta-endotoxins to gypsy moth brush border membrane vesicles is directly correlated to toxicity. J Biol Chem 1995, 270:24719-24724.

30. Van Leeuwen T, Demaeght P, Osborne EJ, Dermauw W, Gohlke S, Nauen R Grbi-ç M, Tirry L, Merzendorfer H, Clark RM: Population bulk segregant mapping uncovers resistance mutations and the mode of action of a chitin synthesis inhibitor in arthropods. Proc Natl Acad Sci 2012, 109:4407-4412.

31. Tabashnik BE, Liu YB, Malvar T, Heckel DG, Masson L, Ballester V, Ménsua JL, Ferré J: Global variation in the genetic and biochemical basis of diamondback moth resistance to Bacillus thuringiensis. Proc Natl Acad SC U S A 1997, 94:12780-12785.

32. Wang $P$, Zhao JZ, Rodrigo-Simón A, Kain W, Janmaat AF, Shelton AM, Ferré J, Myers J: Mechanism of resistance to Bacillus thuringiensis toxin Cry1AC in a greenhouse population of the cabbage looper, Trichoplusia ni. Appl Environ Microbiol 2007, 73:1199-1207.

33. Gassmann AJ, Carriere Y, Tabashnik BE: Fitness costs of insect resistance to Bacillus thuringiensis. Annu Rev Entomol 2009, 54:147-163.

34. Navarro-Cerrillo G, Ferré J, de Maagd RA, Herrero S: Functional interactions between members of the REPAT family of insect pathogen-induced proteins. Insect Mol Biol 2012, 21:335-342.

35. Navarro-Cerrillo G, Hernández-Martínez P, Vogel H, Ferré J, Herrero S: A new gene superfamily of pathogen-response (repat) genes in Lepidoptera: classification and expression analysis. Comp Biochem Physiol B Biochem Mol Biol 2013, 164:10-17.

36. Rodríguez-Cabrera L, Trujillo-Bacallao D, Borrás-Hidalgo O, Wright DJ, Ayra-Pardo C: Molecular characterization of Spodoptera frugiperda-Bacillus thuringiensis Cry1Ca toxin interaction. Toxicon 2008, 51:681-692

37. Liu JB, Tabashnik BE, Pusztai-Carey M: Field-evolved resistance to Bacillus thuringiensis toxin CrylC in diamondback moth (Lepidoptera: Plutellidae). J Econ Entomol 1996, 89:798-804.

38. Hernández-Martinez P, Ferré J, Escriche B: Susceptibility of Spodoptera exigua to 9 toxins from Bacillus thuringiensis. J Invertebr Pathol 2008 97:245-250

39. Hernández-Rodríguez CS, Hernández-Martínez P, Van RJ, Escriche B, Ferré J. Specific binding of radiolabeled Cry1Fa insecticidal protein from Bacillus thuringiensis to midgut sites in lepidopteran species. Appl Environ Microbiol 2012, 78:4048-4050

40. Granero F, Ballester V, Ferré J: Bacillus thuringiensis crystal proteins CRY1Ab and CRY1Fa share a high affinity binding site in Plutella xylostella (L.). Biochem Biophys Res Commun 1996, 224:779-783.

41. Xie X, Cheng T, Wang G, Duan J, Niu W, Xia Q: Genome-wide analysis of the ATP-binding cassette $(A B C)$ transporter gene family in the silkworm, Bombyx mori. Mol Biol Rep 2012, 39:7281-7291.

42. Liu S, Zhou S, Tian L, Guo E, Luan Y, Zhang J, Li S: Genome-wide identification and characterization of ATP-binding cassette transporters in the silkworm. Bombyx mori. BMC Genomics 2011, 12:491.

43. Contreras E, Schoppmeier M, Real MD, Rausell C: Sodium solute symporter and cadherin proteins act as Bacillus thuringiensis Cry3Ba toxin functional receptors in Tribolium castaneum. J Biol Chem 2013, 288:18013-18021.

44. Zúñiga-Navarrete F, Gómez I, Pena G, Bravo A, Soberon M: A Tenebrio molitor GPI-anchored alkaline phosphatase is involved in binding of Bacillus thuringiensis Cry3Aa to brush border membrane vesicles. Peptides 2013, 41:81-86.

45. Jiménez Al, Reyes EZ, Cancino-Rodezno A, Bedoya-Pérez LP, Caballero-Flores GG, Muriel-Millan LF, Likitvivatanavong S, Gill SS, Bravo A, Soberón M: Aedes aegypti alkaline phosphatase ALP1 is a functional receptor of Bacillus thuringiensis Cry4Ba and Cry11Aa toxins. Insect Biochem Mol Biol 2012, 42:683-689.

46. Hua G, Zhang R, Abdullah MA, Adang MJ: Anopheles gambiae cadherin AgCad1 binds the Cry4Ba toxin of Bacillus thuringiensis israelensis and a fragment of AgCad1 synergizes toxicity. Biochemistry 2008, 47:5101-5110.

47. Saengwiman S, Aroonkesorn A, Dedvisitsakul P, Sakdee S, Leetachewa S, Angsuthanasombat C, Pootanakit K: In vivo identification of Bacillus thuringiensis Cry4Ba toxin receptors by RNA interference knockdown of glycosylphosphatidylinositol-linked aminopeptidase $\mathrm{N}$ transcripts in Aedes aegypti larvae. Biochem Biophys Res Commun 2011, 407:708-713. 
48. Likitvivatanavong S, Chen J, Bravo A, Soberon M, Gill SS: Cadherin, alkaline phosphatase, and aminopeptidase $\mathrm{N}$ as receptors of Cry11Ba toxin from Bacillus thuringiensis subsp. jegathesan in Aedes aegypti. Appl Environ Microbiol 2011, 77:24-31.

49. Herrero S, González-Cabrera J, Ferré J, Bakker PL, de Maagd RA: Mutations in the Bacillus thuringiensis Cry1Ca toxin demonstrate the role of domains II and III in specificity towards Spodoptera exigua larvae. Biochem J 2004, 384:507-513.

50. Zhao JZ, Collins HL, Tang JD, Cao J, Earle ED, Roush RT, Herrero S, Escriche B, Ferré J, Shelton AM: Development and characterization of diamondback moth resistance to transgenic broccoli expressing high levels of Cry1C. Appl Environ Microbiol 2000, 66:3784-3789.

51. Van Rie J, Jansens S, Höfte H, Degheele D, Van Mellaert H: Receptors on the brush border membrane of the insect midgut as determinants of the specificity of Bacillus thuringiensis delta-endotoxins. Appl Environ Microbiol 1990, 56:1378-1385

52. Xentari Technical bulletin. Valent Biosciences. http://microbials. valentbiosciences.com/docs/ag-microbials-resources-library/xentari-protoxinblend-technical-bulletin-ag-5398.

53. Public Repository for Seq Crumbs files. https://github.com/JoseBlanca/ seq_crumbs]

54. Haas BJ, Papanicolaou A, Yassour M, Grabherr M, Blood PD, Bowden J, Couger MB, Eccles D, Li B, Lieber M, Macmanes MD, Ott M, Orvis J, Pochet N, Strozzi F, Weeks N, Westerman R, William T, Dewey CN, Henschel R, Leduc RD, Friedman N, Regev A: De novo transcript sequence reconstruction from RNA-seq using the Trinity platform for reference generation and analysis. Nat Protoc 2013, 8:1494-1512.

55. Langmead B, Salzberg SL: Fast gapped-read alignment with Bowtie 2. Nat Methods 2012, 9:357-359.

56. Li H, Durbin R: Fast and accurate short read alignment with BurrowsWheeler transform. Bioinformatics 2009, 25:1754-1760.

57. Koboldt DC, Zhang Q, Larson DE, Shen D, McLellan MD, Lin L, Miller CA Mardis ER, Ding L, Wilson RK: VarScan 2: somatic mutation and copy number alteration discovery in cancer by exome sequencing. Genome Res 2012, 22:568-576.

58. Thompson JD, Gibson TJ, Plewniak F, Jeanmougin F, Higgins DG: The CLUSTAL_X windows interface: flexible strategies for multiple sequence alignment aided by quality analysis tools. Nucleic Acids Res 1997, 25:4876-4882

59. Nicholas KB, Nicholas HBJ, Deerfield DW: GeneDoc: analysis and visualization of genetic variation. EMBNEW NEWS 1997, 4:14

60. Tamura K, Peterson D, Peterson N, Stecher G, Nei M, Kumar S: MEGA5: molecular evolutionary genetics analysis using maximum likelihood, evolutionary distance, and maximum parsimony methods. Mol Biol Evol 2011, 28:2731-2739.

61. Marchler-Bauer A, Zheng C, Chitsaz F, Derbyshire MK, Geer LY, Geer RC, Gonzales NR, Gwadz M, Hurwitz DI, Lanczycki CJ, Lu F, Lu S, Marchler GH, Song JS, Thanki N, Yamashita RA, Zhang D, Bryant SH: CDD: conserved domains and protein three-dimensional structure. Nucleic Acids Res 2013, 41:D348-D352.

62. Bernsel A, Viklund $H$, Hennerdal A, Elofsson A: TOPCONS: consensus prediction of membrane protein topology. Nucleic Acids Res 2009, 37:W465-W468

63. Livak KJ, Schmittgen TD: Analysis of relative gene expression data using real-time quantitative PCR and the 2(-Delta Delta C(T)) method. Methods 2001, 25:402-408.

64. Park B, Kim Y: Transient transcription of a putative RNase containing BEN domain encoded in Cotesia plutellae bracovirus induces an immunosuppression of the diamondback moth, Plutella xylostella. J Invertebr Pathol 2010, 105:156-163.

65. Wolfersberger MG, Luthy P, Maurer A, Parenti P, Sacchi VF, Giordana B, Hanozet GM: Preparation and partial characteritzation of amino acid transporting brush border membrane vesicles from the larval midgut of the cabbage butterfly (Pieris brassicae). Comp Biochem Physiol A Physiol 1987, 86A:301-308.
66. Van Rie J, Jansens S, Höfte H, Degheele D, Van Mellaert H: Specificity of Bacillus thuringiensis delta-endotoxins. Importance of specific receptors on the brush border membrane of the mid-gut of target insects. Eur J Biochem 1989, 186:239-247.

67. Munson PJ, Rodbard D: LIGAND: a versatile computerized approach for characterization of ligand-binding systems. Anal Biochem 1980, 107:220-239.

doi:10.1186/1741-7007-12-46

Cite this article as: Park et al:: ABCC transporters mediate insect resistance to multiple $\mathrm{Bt}$ toxins revealed by bulk segregant analysis. BMC Biology 2014 12:46.

\section{Submit your next manuscript to BioMed Central and take full advantage of:}

- Convenient online submission

- Thorough peer review

- No space constraints or color figure charges

- Immediate publication on acceptance

- Inclusion in PubMed, CAS, Scopus and Google Scholar

- Research which is freely available for redistribution

Submit your manuscript at www.biomedcentral.com/submit
C BioMed Central 